Cite this: RSC Advances, 2013, 3, 7466

Received 10th January 2013, Accepted 12th March 2013

DOI: 10.1039/c3ra41183d

www.rsc.org/advances

\title{
Morphological and crystallographic characteristics of electrodeposited lead from a concentrated electrolyte
}

\author{
Nebojša D. Nikolić, ${ }^{\star a}$ Vesna M. Maksimovićb and Goran Brankovićc \\ Electrodeposition of lead from a concentrated nitrate solution was examined by scanning electron \\ microscopy (SEM) and by X-ray diffraction (XRD) analysis of the obtained powder particles. Single crystals \\ of the (111) preferred orientation were formed at a low overpotential by ohmic controlled \\ electrodeposition. Irregular crystals, needle-like and fern-like dendrites, predominantly of the (111) \\ preferred orientation, were formed at high overpotentials (the diffusion control of the electrodeposition). \\ The ratio of $\mathrm{Pb}$ crystallites oriented in the (200), (220), (311) and (331) planes increased with increasing \\ electrodeposition overpotential. The correlation between the morphologies and crystallographic \\ structures of the lead deposits was discussed by the consideration of general characteristics of growth \\ layers in electrodeposition processes.
}

\section{Introduction}

When considering the dependence of exchange current density, $j_{0}$, and melting point, $T_{\mathrm{m}}$, metals can be classified into three groups. ${ }^{1}$ In the first group are metals, such as Cd, $\mathrm{Zn}$, Sn, Ag (basic solutions) and $\mathrm{Pb}$, characterized by a high exchange current density $\left(j_{0} \rightarrow \infty\right)$ and a low melting point. This group of metals is denoted normal metals. The characteristics of the second group of metals (intermediate metals) are a moderate $T_{\mathrm{m}}$ and a medium $j_{0}$, and metals like $\mathrm{Au}, \mathrm{Cu}$ and $\mathrm{Ag}$ (complex electrolytes) belong to this group. Finally, the third group of metals are inert metals (Fe, Ni, Co, $\mathrm{Pt}, \mathrm{Cr}, \mathrm{Mn}$ ) and they are characterized by a high $T_{\mathrm{m}}$ and a low jo.

The shape of electrochemically formed powder particles strongly depends on the electrodeposition conditions and the nature of the metal. ${ }^{2-4}$ Although dendrites are the most common shape of powder particles obtained by electrolysis, some other morphological forms, such as flakes, fibres, sponges, nanowires and cauliflower-like structures, can be also obtained..$^{2-7}$ The shape of the dendrites of normal metals is completely different from those belonging to the intermediate and inert metals. The 2D (two-dimensional) needlelike and fern-like dendrites, very similar to each other, are usually formed by electrodeposition of normal metals. ${ }^{3}$ These types of powder particles are formed at low overpotentials and

${ }^{a}$ ICTM-Institute of Electrochemistry, University of Belgrade, Njegoševa 12, P.O.B. 473, 11001 Belgrade, Serbia. E-mail: nnikolic@tmf.bg.ac.rs; Fax: +381113370389; Tel: +381113370389

${ }^{b}$ Vinča Institute of Nuclear Sciences, University of Belgrade, P.O.B. 522, 11001 Belgrade, Serbia. E-mail: vesnam@vinca.rs

${ }^{c}$ Institute for Multidisciplinary Research, University of Belgrade, Kneza Višeslava 1a, Belgrade, Serbia. E-mail: goran.brankovic@cms.bg.ac.rs hence use relatively small amounts of energy which is of very high technological significance for the application of electrolysis processes in the production of these metal powders. Different to these types of dendrites, highly branched 3D (three-dimensional) dendrites were formed by the electrodeposition of intermediate ${ }^{3,4,8-13}$ and inert ${ }^{14,15}$ metals. Due to the parallel process of hydrogen evolution, cauliflower-like powder particles are often formed during electrolysis of some intermediate metals $(\mathrm{Cu})^{4,16,17}$ and inert ${ }^{18-22}$ metals.

In contrast to the long-held belief that the electrodeposition of normal metals is a diffusion controlled process across the whole range of overpotentials, investigations performed in recent years showed that electrodeposition of silver ${ }^{23,24}$ and lead $^{3,25}$ can be completely ohmic or a mixed ohmic-diffusion controlled process. ${ }^{26}$ The electrochemical aspects of the formation and growth of lead dendrites are well explored. ${ }^{3,25,26}$ However, there has been no study of the correlation between the surface morphology of lead and its crystallographic structure. For that reason, the aim of this study is to do so.

\section{Experimental}

Lead was electrodeposited from $0.45 \mathrm{M} \mathrm{Pb}\left(\mathrm{NO}_{3}\right)_{2}$ in $2.0 \mathrm{M}$ $\mathrm{NaNO}_{3}$ in an open cell at room temperature. Doubly distilled water and analytical grade chemicals were used for the preparation of the solution for the electrodeposition of lead.

Electrodeposition of lead was performed potentiostatically at overpotentials, $\eta$, of 20, 80 and $140 \mathrm{mV}$. All electrodepositions were performed on vertical cylindrical copper electrodes. The geometric surface area of the copper electrodes was 0.25 $\mathrm{cm}^{2}$. Reference and counter electrodes were made of pure lead. The counter electrode was lead foil with a surface area of 0.80 
$\mathrm{dm}^{2}$ and was placed close to the cell walls. The reference electrode was a lead wire whose tips were positioned at a distance of about $0.2 \mathrm{~cm}$ from the surface of the working electrode. The working electrodes were placed in the centre of the cell, in the same location for each experiment. The quantity of electrodeposited lead was $2.3 \mathrm{~mA} \mathrm{~h} \mathrm{~cm}{ }^{-2}$.

The morphologies of the obtained lead deposits were analyzed by scanning electron microscopy (SEM) using scanning electron microscopes (TESCAN Digital Microscopy and JEOL 5800LV).

$\mathrm{X}$-ray powder diffraction (XRD) analysis performed using a Siemens D500 diffractometer with $\mathrm{Cu}-\mathrm{K} \alpha$ radiation $(\lambda=$ $1.5406 \AA$ A) was used for crystal structure examination.

\section{Results and discussion}

The polarization curve for lead electrodeposition from $0.45 \mathrm{M}$ $\mathrm{Pb}\left(\mathrm{NO}_{3}\right)_{2}$ in $2.0 \mathrm{M} \mathrm{NaNO}_{3}$ (Fig. 1) is a typical representation of ohmic controlled electrodeposition. The main characteristic of this type of electrodeposition process is the linear dependence of the current on the overpotential followed by the fast growth of the current after the inflection point. As seen from Fig. 1, for a lead solution containing $0.45 \mathrm{M} \mathrm{Pb}\left(\mathrm{NO}_{3}\right)_{2}$ in $2.0 \mathrm{M} \mathrm{NaNO}_{3}$, the inflection point corresponds to an overpotential of $55 \mathrm{mV}$.

Fig. 2 shows the morphologies of the lead deposits obtained by ohmic controlled electrodeposition $(\eta=20 \mathrm{mV}$; Fig. $2 \mathrm{a}$ and $\mathrm{b}$ ) and in the zone of the fast current growth after the inflection point of the polarization curve $(\eta=80 \mathrm{mV}$; Fig. 2c and $\mathrm{d}$, and $\eta=140 \mathrm{mV}$; Fig. 2e and f).

From Fig. 2a and b, it can clearly be seen that regular individual crystals of lead were formed in the part of the polarization curve characterized by the linear dependence of the current on the overpotential. Electrodeposition at an overpotential of $80 \mathrm{mV}$ led to the formation of largely irregular individual crystals as shown in Fig. $2 \mathrm{c}$ and d. The increase in

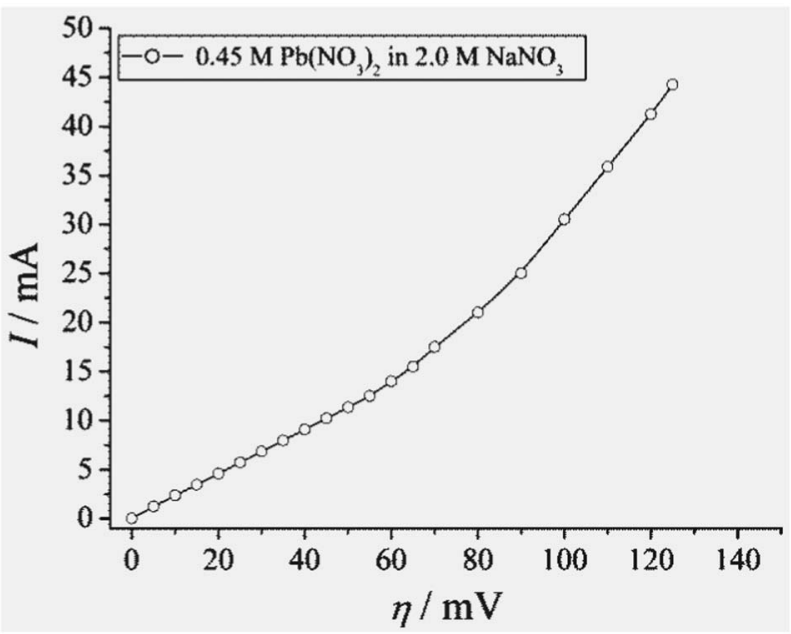

Fig. 1 The polarization curve for lead electrodeposition from $0.45 \mathrm{M} \mathrm{Pb}\left(\mathrm{NO}_{3}\right)_{2}$ in $2.0 \mathrm{M} \mathrm{NaNO}_{3}$. The surface area of the copper working electrode $=0.25 \mathrm{~cm}^{2}$. electrodeposition overpotential from 80 to $140 \mathrm{mV}$ led to the formation of different dendritic forms (Fig. 2e and f). The two types of dendrites formed by electrodeposition at $140 \mathrm{mV}$ were needle-like (Fig. 2e) and fern-like (Fig. 2f) dendrites. The dominant shape of the dendrites formed at an overpotential of $140 \mathrm{mV}$ was needle-like, as the number of fern-like dendrites which formed was smaller than the number of needle-like ones.

In the case of full ohmic control of the electrodeposition, the critical overpotentials for dendritic growth initiation, $\eta_{\mathrm{i}}$ and instantaneous dendritic growth, $\eta_{\mathrm{c}}$ are equal to each other and they correspond to the inflection point of the polarization curve. ${ }^{26}$ After the inflection point, the electrodeposition process is diffusion controlled and the fast increase of the current is due to the formation and growth of dendrites.

Two distinct morphological forms were obtained by the process of lead electrodeposition from the concentrated nitrate solution - the regular individual crystals by ohmic controlled electrodeposition (Fig. $2 \mathrm{a}$ and $\mathrm{b}$ ) and the dendrites from the part of the polarization curve characterized by the fast increase in current after the inflection point (Fig. 2e and f). The irregular crystal forms obtained at an overpotential of 80 $\mathrm{mV}$ (Fig. 2c and d) represent the transitional forms between those obtained at the lower (Fig. 2a and b) and higher (Fig. 2e and f) overpotentials. From Fig. 2c, it can be clearly seen that the irregular crystal developed from a regular crystal. The beginning of the branching of crystals in a dendrite is easy to see from Fig. 2d, showing that this irregular crystal, as well as the other irregular crystals obtained at this overpotential, is a typical dendrite precursor.

The shape of the lead dendrites falls under the classical Wranglen definition of a dendrite. According to Wranglen, ${ }^{27}$ a dendrite consists of a stalk and branches (primary, secondary $e t c$.) and resembles a tree. The flat and fern-like dendrites are referred to as two-dimensional (2D) dendrites. Dendrites comprised of only a stalk and primary branches are referred as primary $(\mathrm{P})$ dendrites. If the primary branches in turn develop secondary branches, the dendrite is called secondary (S). It is very clear from the above consideration that the needle-like dendrites are composed only of stalks (Fig. 2e), while the fern-like dendrites (Fig. 2f) correspond to the primary (P) type. From an electrochemical point of view, a dendrite is defined as an electrode surface protrusion that grows under activation control, while electrodeposition to the macroelectrode is predominantly under diffusion control. ${ }^{24,28-31}$ Then, the sudden and rapid increase of the current on the polarization curve after the inflection point could be ascribed to activation controlled electrodeposition at the tips of the formed dendrite precursors and dendrites, where not only the tips of the stalk but also the tips of primary branches grow under activation control. ${ }^{23-25,28}$

Powder particles for the X-ray diffraction (XRD) analysis were obtained by tapping the lead deposits shown in Fig. 2, and the corresponding XRD patterns are shown in Fig. 3. The crystallites of $\mathrm{Pb}$ obtained at an overpotential of $20 \mathrm{mV}$ were predominately oriented in the (111) plane. The ratio of 


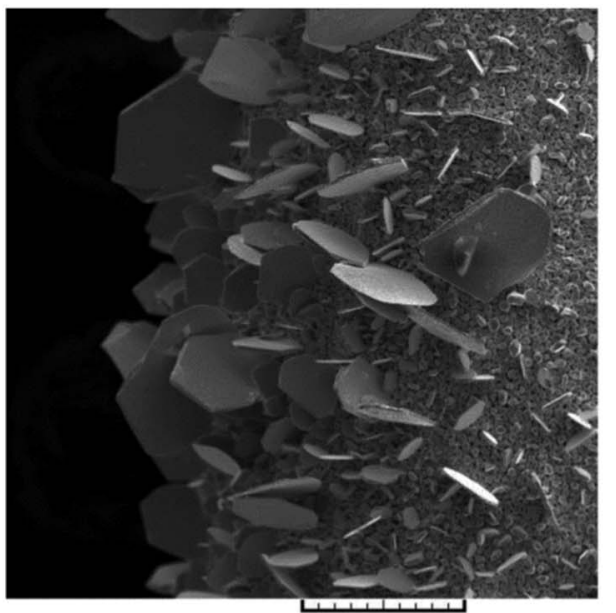

$200 \mu \mathrm{m}$

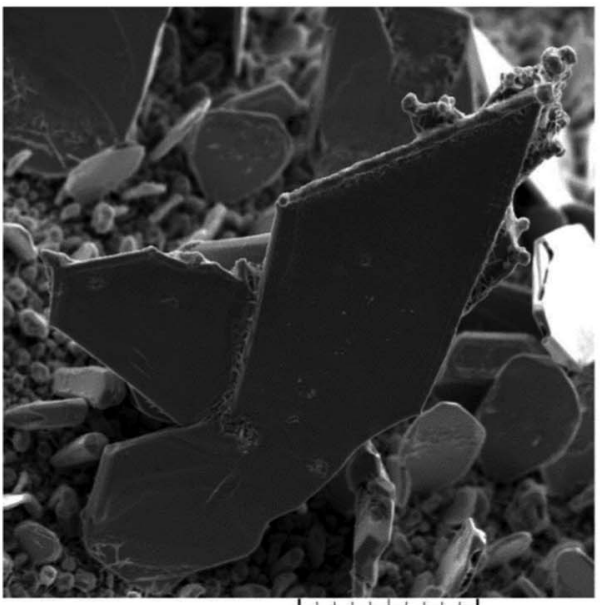

$50 \mu \mathrm{m}$

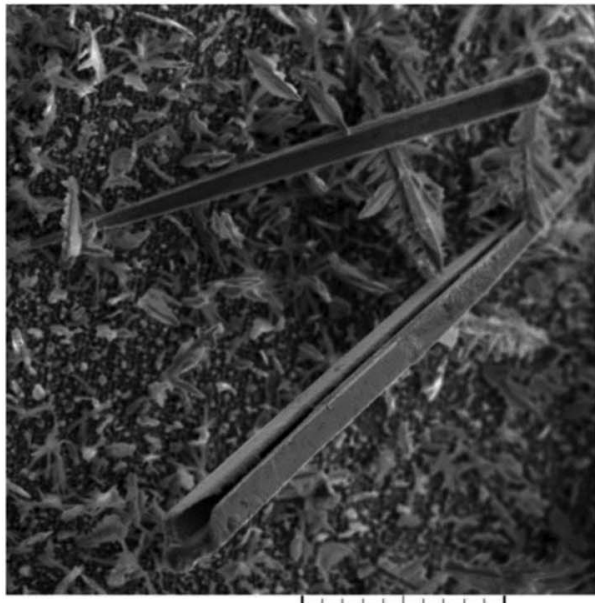

$50 \mu \mathrm{m}$

e) a)

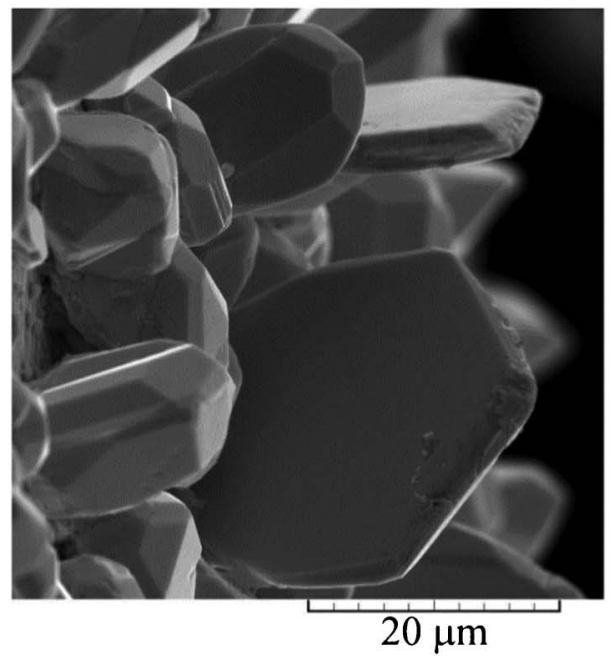

b)

c)

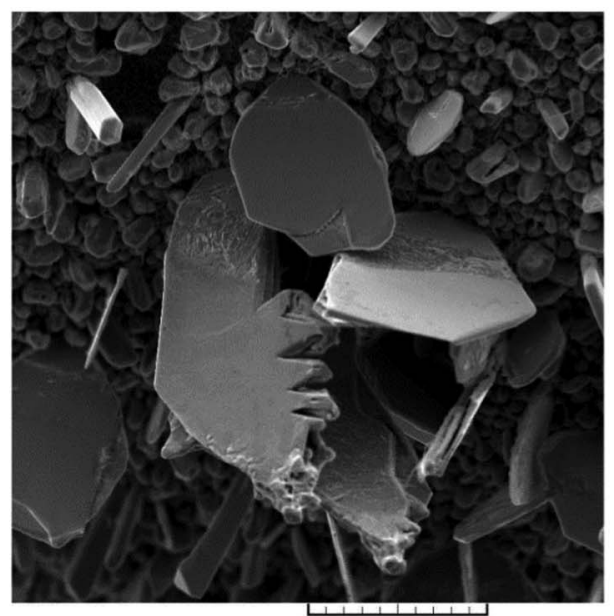

d)

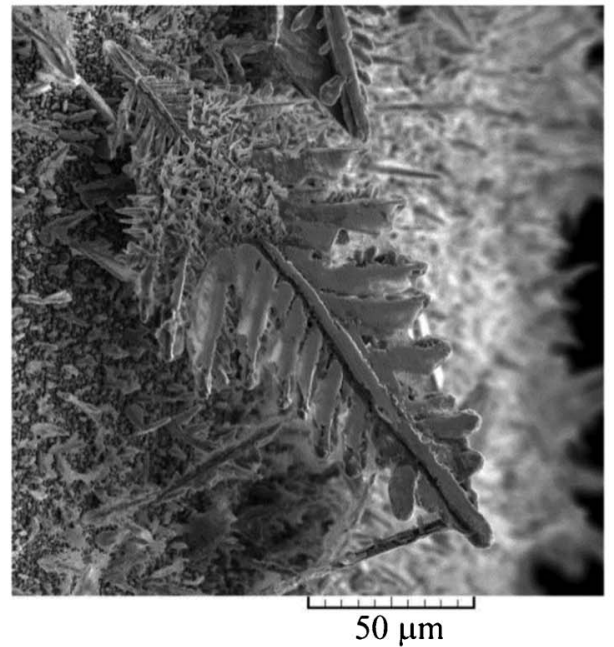

f)

$50 \mu \mathrm{m}$

Fig. 2 Morphologies of the lead deposits electrodeposited at an overpotential of: a) and b) $20 \mathrm{mV}$, c) and d) $80 \mathrm{mV}$, and e) and f) $140 \mathrm{mV}$.

crystallites oriented in the other planes was negligible. Aside from the dominant orientation of $\mathrm{Pb}$ crystallites in the (111) plane, the presence of $\mathrm{Pb}$ crystallites oriented in the (200),
(220), (311) and (331) planes was observed in the XRD patterns of powder particles obtained at overpotentials of 80 and 140 $\mathrm{mV}$. The ratio of crystallites oriented in these planes increased 


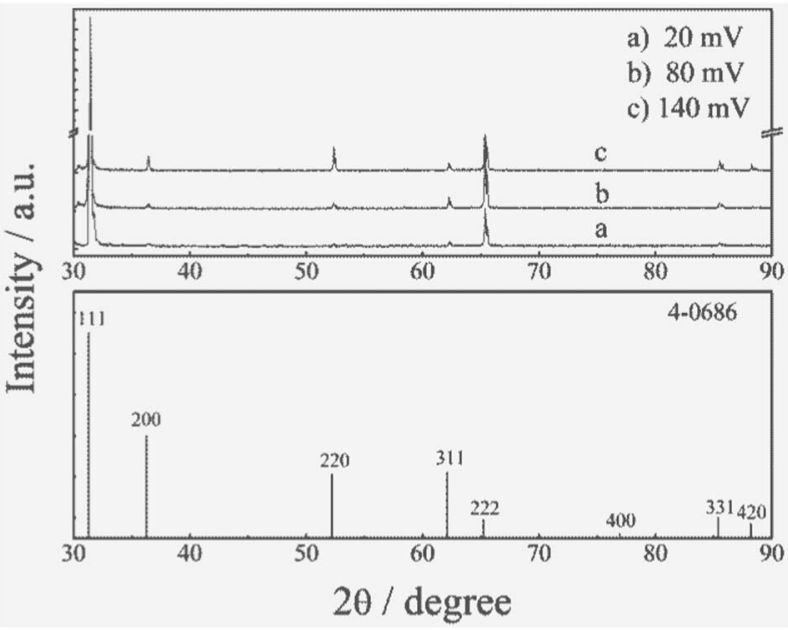

Fig. 3 The XRD patterns of the powder particles obtained by tapping the lead deposits electrodeposited at overpotentials of 20,80 , and $140 \mathrm{mV}$.

with the increase in overpotential from 80 to $140 \mathrm{mV}$. The strongly preferred orientation in the (111) plane was observed in all electrodeposited forms.

Analysis of Fig. 2 and 3 enables correlation of the morphologies of the lead deposits with their crystallographic structures. Then formation of the different morphological forms, from the regular crystals to the different shaped dendrites with the strongly preferred (111) orientation, can be discussed by considering the following general characteristics of growth layers in electrodeposition processes: lead crystallizes in a face-centered cubic (FCC-type) lattice, and Fig. 4 shows a crystal with a simple cubic lattice and (100), (111) and (110) faces. ${ }^{32}$ The planes of the growth layers are the closest packed atom planes of the crystal lattice. ${ }^{27}$ The growth layers start from certain active centres or growth centres on the crystal face. The beginning of growth layers is mainly determined by a current density or overpotential. At low current densities and overpotentials, the growth layers invariably originate in the interior of the crystal faces, and a new layer is not formed until the former has reached the edges of the crystal. At higher current densities and overpotentials when dendrites begin to form, growth centres are also observed at the edges and corners. In this case, new layers are developed before the forerunners have reached their final size so that at certain times a great many layers may be flowing simultaneously.

Hence, the origin of the growth layers is both of growth centres present in the interior of the crystal faces (centre type; these growth layers are formed at low current densities and overpotentials) and of growth centres present on the edges and corners (edge and corner types; these growth layers are formed at high current densities and overpotentials).

The individual regular crystals shown in Fig. $2 \mathrm{a}$ and $\mathrm{b}$ are formed at a low overpotential $(\eta=20 \mathrm{mV})$ and hence, only the growth centres present in the interior of the crystal faces (centre type) are responsible for their formation. During the

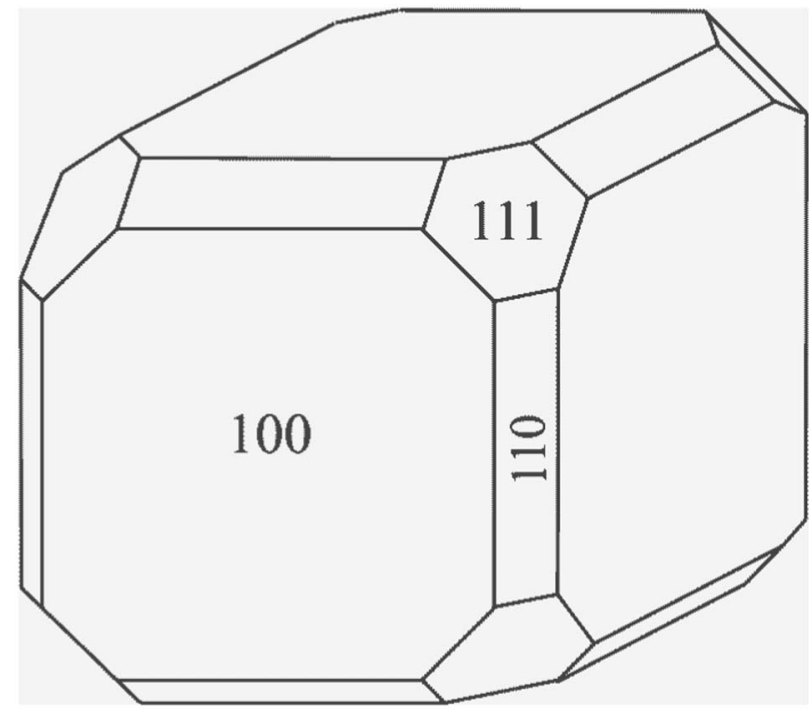

Fig. 4 A crystal with a simple cubic lattice and (100), (111) and (110) faces. (According to ref. 32).

electrodeposition process, the layers flowed rapidly to the edges of the crystal. Several growth centres were present on the surface and the growth layers originating from them grew together completely without discontinuities. As a result of this, a well-developed crystal plate with flat faces and sharp edges and corners, containing angles of $60^{\circ}$ and $120^{\circ}$, is obtained. ${ }^{27}$ The typical hexagonal crystal plates (the parts in the circles) recorded from the side of a regular crystal formed at an overpotential of $20 \mathrm{mV}$ are shown in Fig. 5a. On the basis of the analysis of Fig. 4 and the XRD analysis of $\mathrm{Pb}$ particles electrodeposited at $20 \mathrm{mV}$ ( $\mathrm{Pb}$ crystallites only oriented in the (111) plane), it is clear that these hexagonal crystal faces correspond to the (111) plane. The regular crystals are only constructed from them and hence, they represent single crystals of (111) orientation. Simultaneously, the powder obtained by tapping of the deposit electrodeposited at an overpotential of $20 \mathrm{mV}$ is a collection of $\mathrm{Pb}$ single crystals which is confirmed by X-ray diffraction analysis.

On the other hand, irregular crystals, needle-like and fernlike dendrites are formed by electrodeposition processes at high overpotentials and both types of growth centres are responsible for their formation and growth. The centre type growth layers appear on the sides of the needle-like form because the current density and overpotential is lower on the sides than at the tip of a dendrite. ${ }^{27}$ Inspection of a space lattice model showed that a morphological form may very well be bounded by only (111) faces, as shown in Fig. 5b for a side of one irregular crystal. In this way, the existence of the strongly preferred (111) orientation of powder particles primarily consisting of irregular crystals (precursors of dendrites) and dendrites is very clear (Fig. 2c-f and 3). At higher overpotentials, the growth layers flow slowly and often stop before they have reached the edges of the crystal face. ${ }^{27}$ New layers form which stop even earlier. The growth layers 


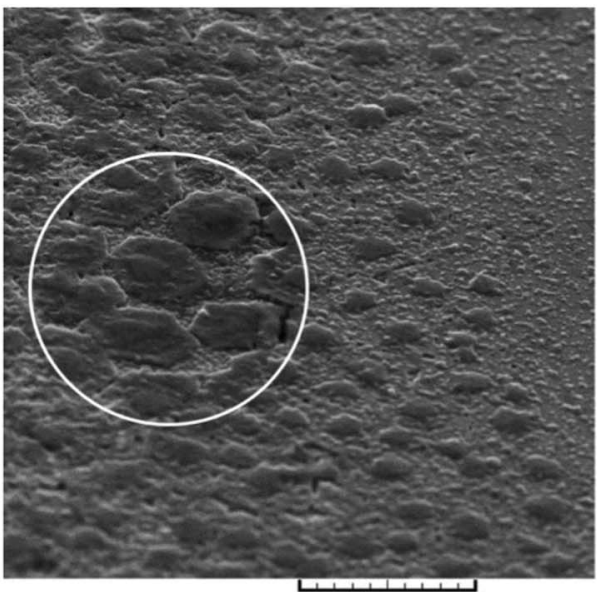

a)

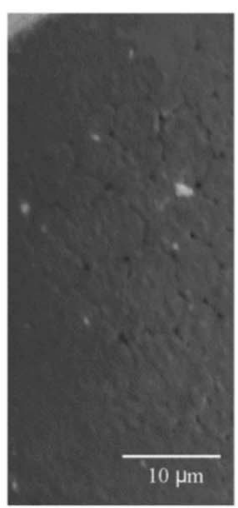

$10 \mu \mathrm{m}$

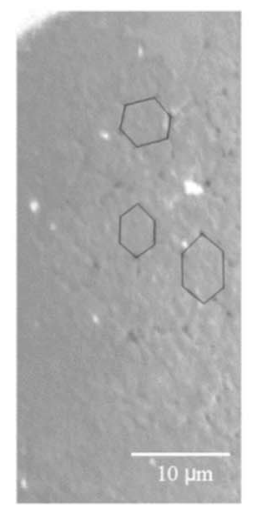

b)

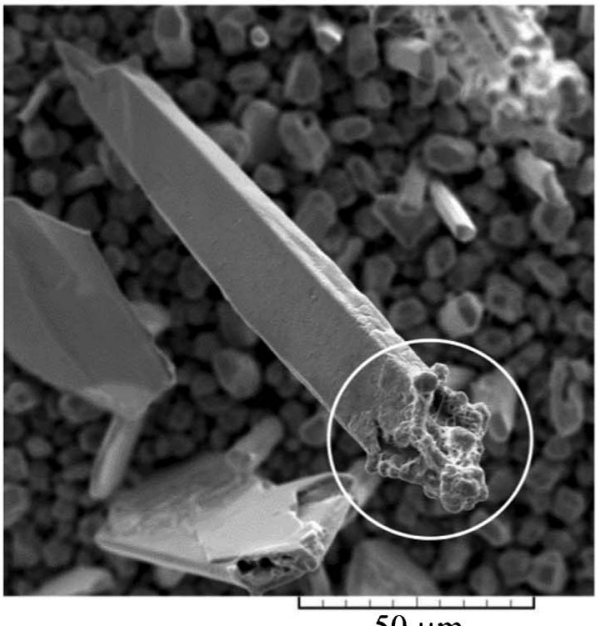

$50 \mu \mathrm{m}$

Fig. 5 The hexagonal growth layers formed at overpotentials of: a) $20 \mathrm{mV}$ and b) $80 \mathrm{mV}$, and c) a rounded tip of the needle-like form electrodeposited at 80 $\mathrm{mV}$.

spread from many centres and they merge incompletely, making rounded edges and corners, as shown in Fig. 5c for the tip of the needle-like form "under construction" (the part in the circle). Hence, it is obvious that the origin of the crystallites oriented in the (200), (220), (311) and (331) planes is from growth centres at the edges and corners. The larger

overpotential, the larger ratio of the lead crystallites oriented in these planes is obtained (Fig. 3).

As already mentioned, the two groups of dendrites formed by electrodeposition at $140 \mathrm{mV}$ are needle-like (Fig. 2e) and fern-like (Fig. 2f). The needle-like dendrites grow along the cube face diagonal [110] of the face-centred cubic lattice. ${ }^{27}$ The fern-like dendrites are constructed from the stalk and primary branches (primary (P) type) with an approximate angle of $60^{\circ}$ between the stalk and the branches. Then, it is obvious that the dendrites branch along the face diagonals [110], of the unit cube which is the most favoured from an energetic point of view. $^{27}$ Due to these characteristics, the fern-like lead dendrites are denoted $2 \mathrm{D}[110] 60^{\circ}$ in Wranglen's classification of a dendrite.

Also, the effect of the current density distribution ${ }^{33}$ should be not excluded when considering dendrite growth because the current lines are primarily concentrated at the tips of these growing needle-like forms.

The different shapes of $\mathrm{Pb}$ deposits, such as octahedral, non-regular crystals, zigzag nanowires and nanoclusters, were synthesized by electrodeposition from complex acetate electrolytes in the galvanostatic regime on different substrates, like $\mathrm{Cu}$, $\mathrm{Ti}$ and $\mathrm{Al}^{34}$ The common characteristics of all these morphological forms is the dominant orientation of $\mathrm{Pb}$ crystallites in the (111) plane. Electron diffraction (ED) studies also confirmed a growth direction in a single zigzag lead nanowire along the [110] axis. $^{34}$

It can be concluded from the aforementioned considerations that the final morphology of electrodeposited metal (in this case, $\mathrm{Pb}$ ) is determined by the current density or overpotential applied, the composition of solution, the type of working electrode, temperature, etc., while the interior structure of these surface morphologies is only determined by the characteristics and nature of metal, and it does not depend on the electrodeposition conditions. In our case, the morphologies of the lead deposits were substantially different, but the strongly preferred (111) orientation was always obtained.

\section{Conclusions}

A correlation between the morphology and the crystallographic structure of electrodeposited lead was made by X-ray diffraction and scanning electron microscopic (SEM) analyses of the obtained deposits.

The characteristic indicator of ohmic controlled electrodeposition was the formation of single crystals of the (111) preferred orientation. The irregular different shaped crystals (precursors of dendrites), as well as the needle-like and fernlike dendrites formed at overpotentials characterized by the fast increase of the current after the inflection point showed the strongly preferred (111) orientation. Aside from lead crystallites oriented in the (111) planes, the presence of crystallites oriented in the (200), (220), (311) and (331) planes was also observed in these dendritic forms. The ratio of 
crystallites oriented in these crystal planes increased with the increasing electrodeposition overpotential.

The role of the growth centres in the development of the final morphologies of the lead deposits was presented. The growth centres present in the interior of the crystal faces were a cause of the orientation of crystallites in the (111) plane. The appearance of crystallites oriented in the (200), (220), (311) and (331) planes was ascribed to growth centres on the edges and corners.

\section{Acknowledgements}

The work was supported by the Ministry of Education, Science and Technological Development of the Republic of Serbia under the research project: "Electrochemical synthesis and characterization of nanostructured functional materials for application in new technologies"' (No. 172046).

\section{References}

1 R. Winand, Electrochim. Acta, 1994, 39, 1091.

2 M. G. Pavlović and K. I. Popov, Electrochem. Encyclopedia, 2005.

3 V. D. Jović, N. D. Nikolić, U. Č. Lačnjevac, B. M. Jović and K. I. Popov, Morphology of Different Electrodeposited Pure Metal Powders, in Electrochemical Production of Metal Powders, Series: Modern Aspects of Electrochemistry, ed. S. S. Djokić, Springer, 2012, vol. 54, pp. 63-123.

4 N. D. Nikolić and K. I. Popov, Electrodeposition of Copper Powders and Their Properties, in Electrochemical Production of Metal Powders, Series: Modern Aspects of Electrochemistry, ed. S. S. Djokić, Springer, 2012, vol. 54, pp. 125-185.

5 Y. Ni, Y. Zhang, L. Zhang and J. Hong, CrystEngComm, 2011, 13, 794.

6 M. Yang, J. Mater. Chem., 2011, 21, 3119.

7 C. Ding, C. Tian, R. Krupke and J. Fang, CrystEngComm, 2012, 14, 875 .

8 S. S. Djokić, N. D. Nikolić, P. M. Živković, K. I. Popov and N. S. Djokić, ECS Trans., 2011, 33, 7.

9 G. Orhan and G. Hapci, Powder Technol., 2010, 201, 57.

10 G. Orhan and G. G. Gezgin, J. Serb. Chem. Soc., 2012, 77, 651.

11 T.-H. Lin, C.-W. Lin, H.-H. Liu, J.-T. Sheu and W.-H. Hung, Chem. Commun., 2011, 47, 2044.

12 J. Han and J. Liu, J. Nanoeng. Nanomanuf., 2012, 2, 171.

13 M. V. Mandke, S.-H. Han and H. M. Pathan, CrystEngComm, 2012, 14, 86.
14 J. Wang, L. Wei, L. Zhang, Y. Zhang and C. Jiang, CrystEngComm, 2012, 14, 1629.

15 N. D. Nikolić, H. Wang, H. Cheng, C. Guerrero, E. V. Ponizovskaya, G. Pan and N. Garcia, J. Electrochem. Soc., 2004, 151, C577.

16 N. D. Nikolić, Lj. J. Pavlović, M. G. Pavlović and K. I. Popov, Powder Technol., 2008, 185, 195.

17 N. D. Nikolić, G. Branković and M. G. Pavlović, Powder Technol., 2012, 221, 271.

18 L. Vázquez-Gómez, E. Verlato, S. Cattarin, N. Comisso, P. Guerriero and M. Musiani, Electrochim. Acta, 2011, 56, 2237.

19 V. M. Maksimović, Lj. J. Pavlović, B. M. Jović and M. G. Pavlović, J. Serb. Chem. Soc., 2008, 73, 861.

20 Lj. J. Pavlović, M. M. Pavlović, M. G. Pavlović, N. D. Nikolić and M. V. Tomić, Int. J. Electrochem. Sci., 2010, 5, 1898.

21 V. D. Jović, B. M. Jović, V. M. Maksimović and M. G. Pavlović, Electrochim. Acta, 2007, 52, 4254.

22 V. D. Jović, V. M. Maksimović, M. G. Pavlović and K. I. Popov, J. Solid State Electrochem., 2005, 10, 373.

23 K. I. Popov, P. M. Živković, S. B. Krstić and N. D. Nikolić, Electrochim. Acta, 2009, 54, 2924.

24 K. I. Popov and N. D. Nikolić, General Theory of Disperse Metal Electrodeposits Formation, in Electrochemical Production of Metal Powders, Series: Modern Aspects of Electrochemistry, ed. S. S. Djokić, Springer, 2012, vol. 54, pp. 1-62.

25 N. D. Nikolić, G. Branković and U. Lačnjevac, J. Solid State Electrochem., 2012, 16, 2121.

26 N. D. Nikolić, K. I. Popov, P. M. Živković and G. Branković, J. Electroanal. Chem., 2013, 691, 66.

27 G. Wranglen, Electrochim. Acta, 1960, 2, 130.

28 K. I. Popov, P. M. Živković and N. D. Nikolić, The Effect of Morphology of Activated Electrodes on their Electrochemical Activity, in Electrodeposition: Theory and Practice, Series: Modern Aspects of Electrochemistry, ed. S. S. Djokić, Springer, 2010, vol. 48, pp. 163-213.

29 K. I. Popov, S. S. Djokić and B. N. Grgur, Fundamental aspects of electrometallurgy, Kluwer Academic/Plenum Publishers, New York, 2002.

30 A. R. Despić and K. I. Popov, Transport controlled deposition and dissolution of metals, in Modern Aspects of Electrochemistry, ed. B. E. Conway and J. O‘ M. Bockris, Plenum Press, New York, 1972, vol. 7, pp. 199-313.

31 J. W. Diggle, A. R. Despic and J. O‘ M. Bockris, J. Electrochem. Soc., 1969, 116, 1503.

32 A. Milchev, Electrocrystallization, Fundamentals of Nucleation and Growth, Kluwer Academic Publishers, Boston/Dordrecht/London, 2002, p. 24.

33 K. I. Popov, P. M. Živković and N. D. Nikolić, J. Serb. Chem. Soc., 2011, 76, 805.

34 C.-Z. Yao, M. Liu, P. Zhang, X.-H. He, G.-R. Li, W.-X. Zhao, P. Liu and Y.-X. Tong, Electrochim. Acta, 2008, 54, 247. 